\title{
Human rhinovirus serotypes induces different immune responses
}

\author{
Ji Heui Kim, Jung Yeon Jang and Yong Ju Jang ${ }^{*}$ (10)
}

\begin{abstract}
Background: Different species of human rhinovirus (HRV) can induce varied antiviral and inflammatory responses in human blood macrophages and lower airway epithelium. Although human nasal epithelial cells (HNECs) are a primary infection route of HRV, differences between major and minor groups of HRV in the upper airway epithelium have not been studied in detail. In this study, we investigated viral replications and immune responses of major and minor groups of HRV in the HNECS.

Methods: Viral replication, immune responses of IFN- $\beta$, IFN- $\lambda$, proinflammatory cytokines, and viral receptors, and mRNA expression of transcription factors of HRV16 (major group) and HRV1B (minor group) in the HNECs were assessed.
\end{abstract}

Results: Compared with HRV16, HRV1B replicated more actively without excessive cell death and produced higher IFN- $\beta$, IFN- $\lambda 1 / 3, C X C L 10$, IL-6, IL-8, and IL-18 levels. Furthermore, low-density lipoprotein receptor (LDLR), TLR3, MDA5, NF-KB, STAT1, and STAT2 mRNA levels increased in HRV1B-infected HNECS.

Conclusion: HRV1B induces a stronger antiviral and inflammatory response from cell entry to downstream signaling compared with HRV16.

Keywords: Human rhinovirus, Interferon, IL-8, TLR3, MDA5, NF-kB, Cytokines

\section{Background}

Human rhinovirus (HRV) is the most common cause of the common cold. Furthermore, HRV is detected in the nasal lavage and mucosae as well as turbinate epithelial cells of patients with chronic rhinosinusitis (CRS), suggesting a significant association between HRV infection and pathogenesis of CRS [1,2]. HRV infections can also trigger severe lower airway diseases such as bronchitis, pneumonia, and exacerbations of asthma and chronic obstructive pulmonary disease [3-7].

HRVs are classified phylogenetically into three species (A, B, and C), including around 160 serotypes that differ in their surface proteins [8]. Different receptors between

*Correspondence: jangyj@amc.seoul.kr

Department of Otorhinolaryngology - Head and Neck Surgery, Asan Medical Center, University of Ulsan College of Medicine, 88 Olympic-ro

43-gil, Songpa-gu, Seoul 05505, Republic of Korea major and minor groups of HRV can elicit different immune and inflammatory responses. The major groups HRV-A and HRV-B enter the respiratory epithelial cells via Inter-Cellular Adhesion Molecule 1 (ICAM-1, CD54), whereas minor group HRV uses the low-density lipoprotein receptor (LDLR) [8]. HRV-C binds to cadherinrelated family member 3 [9]. After their internalization via ICAM-1 or LDLR, the RNA genome of HRV crosses the endosome membrane into the cytosol [10]. In the endosome, viral double-stranded RNA (dsRNA) and single-stranded RNA (ssRNA) are recognized by toll-like receptor 3 (TLR3) and TLR7/8, respectively. Newly synthesized viral dsRNA and ssRNA in the cytoplasm are also recognized by retinoic acid-inducible gene I (RIG-I) and melanoma differentiation-associated gene 5 (MDA5). TLRs, RIG- 1 , and MDA- 5 stimulate interferon- $\beta$ (IFN- $\beta$ ) and INF- $\lambda$ responses and production of proinflammatory cytokines and their gene expression, including $\mathrm{C}-\mathrm{X}-\mathrm{C}$ original author(s) and the source, provide a link to the Creative Commons licence, and indicate if changes were made. The images or other third party material in this article are included in the article's Creative Commons licence, unless indicated otherwise in a credit line to the material. If material is not included in the article's Creative Commons licence and your intended use is not permitted by statutory regulation or exceeds the permitted use, you will need to obtain permission directly from the copyright holder. To view a copy of this licence, visit http://creativecommons.org/licenses/by/4.0/. The Creative Commons Public Domain Dedication waiver (http://creativeco mmons.org/publicdomain/zero/1.0/) applies to the data made available in this article, unless otherwise stated in a credit line to the data. 
motif chemokine 10 (CXCL10), interleukin (IL)-6, and IL-8/CXCL8 [11, 12]. In a previous study, HRV16 (major group) and HRV1A (minor group) infections induced phosphorylation of kinases (p38, JNK, ERK5) and transcription factors (ATF-2, CREB, CEBP-alpha) differently in human macrophages derived from blood. Differential activation of these signaling pathways led to altered expression of inflammatory cytokines Chemokine $(\mathrm{C}-\mathrm{C}$ motif) ligand 20 (CCL20), CCL2, and IL-10 [13].

Although human nasal epithelial cells (HNECs) are a primary infection route of HRV, there are no reports stating the differences in the inflammatory responses between major and minor groups of HRV in the HNECs. Minor group HRV1B can be infected in the lungs and sinonasal mucosa in Balb/c mice and induce airway inflammation [14, 15]. In our previous studies, it was identified that major group HRV16 induces inflammatory responses and alters tight and adherens junctions in HNECs, which may have deleterious effects on the barrier function of HNECs [16-18]. In addition, HRV16 infection up-regulates bacterial adhesion to HNECs, may induce secondary bacterial infections leading to bacterial rhinosinusitis [19-21]. In another previous study, HRV-A and HRV-B were detected in the nasal lavage fluid and turbinate epithelial cells of patients with CRS, and only HRV-A in the non-CRS controls [22]. Therefore, we focused on HRV1B (minor group of HRV-A) and HRV16 (major group of HRV-A) in the upper airway epithelium, and studied the immune responses elicited by both HRV16 and HRV1B infected cells, assessed the viral replications and measured the levels of IFN- $\beta$, IFN- $\lambda$, and proinflammatory cytokines produced by the infected cells.

\section{Methods}

\section{Air-liquid interface (ALI) culture and virus infection in HNECs}

This study was conducted in accordance with the Declaration of Helsinki and approved by the Institutional Review Board of Asan Medical Center (2017-0668). All participants provided written informed consent for inclusion before they participated in the study. HNECs were obtained from the middle turbinate of eight healthy subjects (4 males and 4 females, ages 19-49) who underwent septoplasty, according to a previous study [23]. They had no history of allergy and asthma, upper respiratory infection, and systemic or topical corticosteroid or antibiotic medications for 4 weeks before surgery. Briefly, passage- 2 HNECs $\left(3 \times 10^{5}\right.$ cells/well $)$ were seeded in $0.5 \mathrm{ml}$ of culture medium on Transwell clear culture inserts $(24 \mathrm{~mm}$, with a $0.4-\mu \mathrm{m}$ pore size; Costar; Corning Inc., Corning, NY). Cells were cultured in a 1:1 mixture of basal epithelial growth medium and Dulbecco's modified Eagle's medium containing previously described supplements [23]. Cultures were grown in the submerged state for the first 9 days. The culture medium was changed on the first day, and thereafter, every alternate day. On day 9 , the apical medium was removed to create an ALI, and cultures were supplied from the basal compartment only. All experiments described here used HNECs on day 14 after ALI creation, and their differentiation was confirmed by increased TEKT1 and MUC5AC mRNA expression levels and decreased SPRR1 mRNA levels and immunofluorescence staining for $\alpha$-tubulin and MUC5AC.

HRV16 (major group) and HRV1B (minor group) (American Type Culture Collection, Manassas, VA) were grown and titered in HeLa cells as previously described [24]. HNECs were either mock-infected with phosphate buffered saline (PBS) or inoculated with HRV16 or HRV1B at a multiplicity of infection of 0.5 for $4 \mathrm{~h}$ at $33^{\circ} \mathrm{C}$, and washed with PBS. Cells were then incubated at $37^{\circ} \mathrm{C}$ in $5 \% \mathrm{CO} 2$ for $72 \mathrm{~h}$.

\section{Real-time PCR}

Total RNA was isolated from HNECs infected with HRV16 and HRV1B on the third day using RNeasy Mini Kit (Qiagen, Hilden, North Rhine-Westphalia, Germany) according to the manufacturer's instructions.

Viral RNA was quantified using an HRV16 or HRV1B Genesig $^{\circledR}$ standard kit (Primerdesign ${ }^{\text {TM }}$ Ltd., Chandler's Ford, UK). HRV RNA standards with pre-determined copy numbers included in the kit were used to generate standard curves for the quantification of HRV16 or HRV1B RNA. Real time-PCR was performed on an Applied Biosystems 7500 Fast Real-Time PCR instrument (Life Technologies Inc., Burlington, ON, Canada).

cDNA was synthesized using RT-\&GO ${ }^{\mathrm{TM}}$ Mastermix (MP Biomedicals, Santa Ana, CA) according to the manufacturer's protocol. Quantitative real-time PCR was performed using each cDNA with the Light-Cycler 480 SYBR Green I Master (Roche, Mannheim, Germany). The reaction mixture was prepared by the addition of a primer set to a LightCycler ${ }^{\circledR}$ real-time PCR system (Roche) following the manufacturer's instructions. PCR Primer sets for ICAM-1, LDLR, TLR3, TLR4, TLR7, TLR8, RIG-I, MDA5, signal transducer and activator of transcription 1 (STAT1), STAT2, nuclear factor kappalight-chain-enhancer of activated B cells (NK- $\mathrm{B} B$ ), IFN regulatory factor 3 (IRF3), IFR7, IRF9, and glyceraldehyde-3-phosphate dehydrogenase (GAPDH) are listed in Table 1. Reaction conditions were as follows: initial denaturation at $95^{\circ} \mathrm{C}$ for $5 \mathrm{~min}$, followed by 45 cycles of denaturation at $95^{\circ} \mathrm{C}$ for $10 \mathrm{~s}$, annealing at $55^{\circ} \mathrm{C}$ for $20 \mathrm{~s}$, and extension at $72{ }^{\circ} \mathrm{C}$ for $10 \mathrm{~s}$. Melting temperature analysis was also performed $\left(65-95{ }^{\circ} \mathrm{C}\right.$ at $0.5{ }^{\circ} \mathrm{C}$ increments for reading the fluorescent signals). To analyze the data, we 
Table 1 Primer sequences used real-time PCR

\begin{tabular}{ll}
\hline Genes & Primer sequences \\
\hline ICAM-1 & $\begin{array}{l}\text { Forward 5'-GCAGACAGTGACCATCTACAGCTT-3' } \\
\text { Reverse 5'-CTTCTGAGACCTCTGGCTTCGT-3' }\end{array}$ \\
LDL-R & Forward 5'-GACGTGGCGTGAACATCTC-3' \\
& Reverse 5'-CTGGCAGGCAATGCTTTGG-3' \\
TLR3 & Forward 5'-TTTGCGAAGAGGAATGTTTAAATCT-3' \\
& Reverse 5'-CACCTATCCGTTCTTTCTGAACTG-3' \\
RIG-1 & Forward 5'-GCTGATGAAGGCATTGACATTG-3' \\
& Reverse 5'-CAGCATTACTAGTCAGAAGGAAGCA-3' \\
MDA-5 & Forward 5'-CCCATGACACAGAATGAACAAAA-3' \\
& Reverse 5'-CGAGACCATAACGGATAACAATGT-3' \\
NK-KB & Forward 5'-CCATGACAGCAAATCTCC-3' \\
& Reverse 5'-TAAACTTCATCTCCACCCC-3' \\
IRF3 & Forward 5'-TCTTCCAGCAGACCATCTCC-3' \\
& reverse 5'-TGCCTCACGTAGCTCATCAC-3' \\
IRF7 & Forward 5'-TACCATCTACCTGGGCTTCG-3' \\
& Reverse 5'-TGCTGCTATCCAGGGAAGAC-3' \\
STAT1 & Forward 5'-ATCAGGCTCAGTCGGGGAAT-3' \\
& Reverse 5'-TGGTCTCGTGTTCTCTGTTCTGC-3' \\
STAT2 & Forward 5'-GCCCTAGTTCCAGCTCTAATG-3' \\
& Reverse 5'-CAGGCTCATTGTGGTCTCTAAT-3' \\
IRF9 & Forward 5'-CCCGAAAACTCCGGAACTG-3' \\
& Reverse 5'-CAGCACACTCCGGGAACT-3' \\
GAPDH & Forward 5'-GACCCCTTCATTGACCTC-3' \\
& Reverse 5'-GCTAAGCAGTTGGTGGTG-3' \\
\hline
\end{tabular}

used LightCycler ${ }^{\circledR} 480$ software, Version 1.5 (Roche). The results were normalized to GAPDH expression, and the relative gene expression was calculated using the comparative $2^{-\Delta \Delta C T}$ method.

\section{Measurement of lactate dehydrogenase}

Lactate dehydrogenase (LDH) activity was measured to evaluate degree of cell death caused by viral infection using the LDH assay kit (BioVision, Mountain View, CA, USA) according to the manufacturer's protocol.

\section{Immunofluorescence staining}

Fixed and permeabilized cells were incubated with diluted mabJ2 in PBS/1\% BSA $(0.33 \mu \mathrm{g} / \mathrm{ml}$, which corresponded to a 1:1500 dilution of the antibody at $0.5 \mathrm{mg} /$ $\mathrm{ml}$ ) at room temperature for $1 \mathrm{~h}$. Cells were washed twice with PBS. The R16-7 monoclonal antibody (mAb) (QED Bioscience Inc., San Diego, CA) recognizes the capsid protein VP2 and its precursor VP0 and P1 of RV16. R16-7 $\mathrm{mAb}$ at $10 \mu \mathrm{g} / \mathrm{ml}$ and anti-serum HRV1B at $5 \mu \mathrm{g} /$ $\mathrm{ml}$ were incubated at $4{ }^{\circ} \mathrm{C}$ overnight. Antiserum against HRV1B was raised to HRV1B-infected HeLa whole cell lysates. The antiserum was partially purified by incubating with nitrocellulose-bound HeLa cell proteins. The cells were then incubated with secondary antibody Alexa Fluor $^{\circledR} 488$ donkey anti-mouse IgG $(20 \mu \mathrm{g} / \mathrm{ml}$; Abcam, Cambridge, UK) to R16-7 mAb and Alexa Fluor ${ }^{\circledR} 488$ goat anti-guinea pig IgG $(7 \mu \mathrm{g} / \mathrm{ml}$; Invitrogen, Carlsbad, CA, USA) to anti-serum HRV1B for $60 \mathrm{~min}$ at $24{ }^{\circ} \mathrm{C}$ in the dark. Controls were incubated with the same concentrations of mouse IgG isotype control (Invitrogen) and guinea pig IgG isotype control (Invitrogen). Cells were stained with 4,6-diamidino-2-phenylindole (DAPI; Invitrogen), mounted with proLong antifade medium (Invitrogen), and examined using a confocal laser scanning microscope (ZEISS LSM 780; Carl Zeiss Microscopy GmbH, Jena, Germany). The fluorescence intensity of Alexa Fluor ${ }^{\circledR} 488$ was quantified by ImageJ (National Health Institute, Bethesda, MA, USA).

\section{ELISA}

IFN- $\beta$, IFN- $\lambda 1 / 3$, CXCL10, IL-6, IL- 8 , and IL-18 concentrations in the basal supernatants were measured with a human DuoSet ELISA kit (R\&D Systems, Minneapolis, $\mathrm{MN}, \mathrm{USA}$ ) according to the manufacturer's instructions.

\section{Statistical analysis}

The variables were compared using a paired Wilcoxon signed-rank test. The significance of a correlation was assessed using the Pearson's correlation test. Data were analyzed using GraphPad Prism v.9.00 (GraphPad Software Inc.). Statistical significance was defined at $P<0.05$.

\section{Results}

\section{HRV16 and HRV1B replication}

Initially, we checked the viral RNA and LDH activity after HRV16 infection in A549 cell lines, which is a human epithelial cell line derived from a lung carcinoma tissue, at $24,48,72$, and $96 \mathrm{~h}$ incubated at $33^{\circ} \mathrm{C}$ and $37^{\circ} \mathrm{C}$ after infection for $4 \mathrm{~h}$ at $33{ }^{\circ} \mathrm{C}$. HRV16 RNA was highest at $24 \mathrm{~h}$ post-infection and decreased slightly, but remained until $72 \mathrm{~h}$ post-infection without statistical significance. There was no significant difference in HRV16 RNA between $33{ }^{\circ} \mathrm{C}$ and $37{ }^{\circ} \mathrm{C}$ incubation temperature. However, LDH activity was significantly increased in incubated cells at $33{ }^{\circ} \mathrm{C}$ from 24 to $96 \mathrm{~h}$, but not significantly different between $24,48,72$, and $96 \mathrm{~h}$ post-infection in incubated cells at $37{ }^{\circ} \mathrm{C}$ (Additional file 1: Fig. S1a). The IFN- $\lambda 1 / 3$ and IL- 6 levels consistently increased from 24 to $72 \mathrm{~h}$ and remained unchanged from 72 to $96 \mathrm{~h}$ (Additional file 1: Fig. S1b). Hence, we focused on the immune response to HRV infections in HNECs at $72 \mathrm{~h}$ and determined $37{ }^{\circ} \mathrm{C}$ of incubation temperature considering the significantly increased cytotoxicity at $33^{\circ} \mathrm{C}$.

In addition, to determine the viral load, submerged primary nasal epithelial cells were infected with 0.5 and 1 MOI HRV16, and HRV16 RNA at $72 \mathrm{~h}$ and LDH activity and IFN- $\beta$, IFN- $\lambda 1 / 3$, IL-6 levels after HRV16 infection were measured at 24,48 , and $72 \mathrm{~h}$ post-infection (Additional file 1: Fig. S2). HRV RNA, LDH activity, and 
IFN- $\beta$ levels were not different between cells infected with $0.5 \mathrm{MOI}$ and cells infected with $1 \mathrm{MOI}$ in all time points. Although IFN- $\lambda 1 / 3$ and IL- 6 levels were higher in cells in cells infected with $0.5 \mathrm{MOI}$ or $1 \mathrm{MOI}$ compared to uninfected cells at each time point, there were no differences between cells infected with $0.5 \mathrm{MOI}$ and cells infected with $1 \mathrm{MOI}$ in all time points. Therefore, $0.5 \mathrm{MOI}$ of HRV was determined considering viral replication, cell cytotoxicity, and cytokine production.

At $72 \mathrm{~h}, \mathrm{HRV} 16$ and HRV1B RNA in the infected cells increased $(p=0.008$ and $p=0.012$, respectively) compared to that of the mock; the replication of HRV1B RNA was higher than that of HRV16 $(p=0.016)$ (Fig. 1a). LDH activity remained similar across the mock and HRV16 infections, while showing a slight increase in HRV1B infections (all $p>0.05$ ) (Fig. 1b). Immunofluorescence staining revealed that HRV1B was more abundant in the cytoplasm of HNECs than HRV16, and fluorescence intensity was higher in HRV1B than in HRV16 $(p=0.008)$ (Fig. 1c, d).
Interferon and proinflammatory cytokine production IFN- $\beta$ production significantly increased in HRV1B infection $(p=0.028)$, but not in HRV16 infection $(p=0.465)$, whereas IFN- $\lambda 1 / 3$ production increased in both HRV16 and HRV1B infections $(p=0.011$ and $p=0.017$, respectively). IFN- $\beta$ and IFN- $\lambda 1 / 3$ levels in HRV1B-infected cells were higher than those in HRV16-infected cells $(p=0.043$ and $p=0.028$, respectively) (Fig. 2a, b).

The production of proinflammatory cytokines CXCL10 and IL- 6 increased in both HRV16 and HRV1B infection ( $p<0.05$ for each), whereas IL- 8 and IL-18 production increased in HRV1B infection $(p=0.025$ and $p=0.018$, respectively), but not in HRV16 infection ( $p=0.314$ and $p=0.674$, respectively). IL- 6 and IL- 8 levels in HRV1B were higher than HRV16 levels $(p=0.018$ and $p=0.018$, respectively) (Fig. 2c-f).

IFN $-\beta$, IFN $-\lambda 1 / 3$, and IL- 18 levels positively correlated with HRV RNA copy number $(p=0.002, p<0.001$, and $p=0.006$, respectively), and IL-6 and IL-8 levels positively correlated with the fluorescence intensity of HRV $(p=0.003$ and $p=0.040$, respectively) (Fig. 3a, b). a

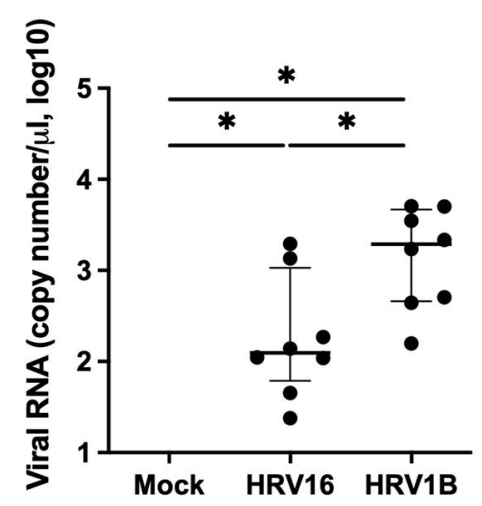

C

HRV16

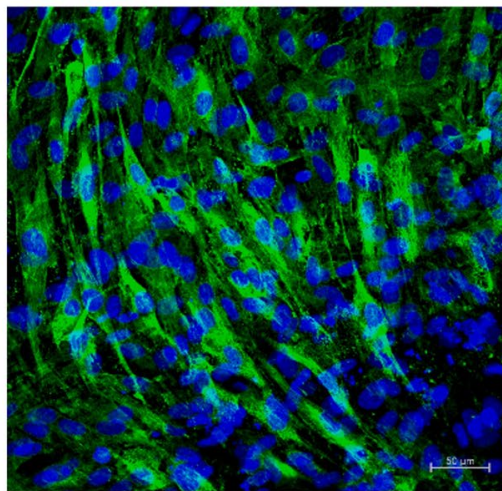

b

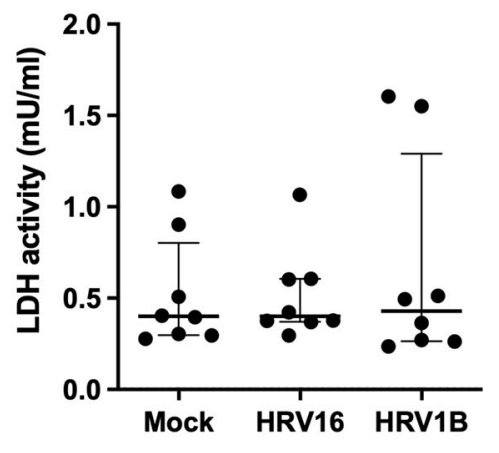

HRV1B

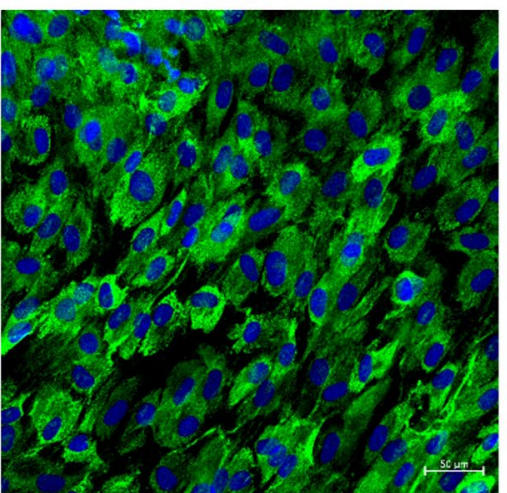

d

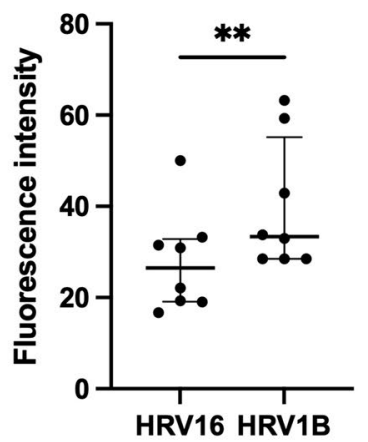

Fig. 1 Viral RNA in HRV16 and HRV1B-infected HNECs at 72 h. a Copy number of HRV1B RNA was higher than that of HRV16 RNA. b LDH activity in HRV16 and HRV1B infected HNECs were not different with that in mock-infected HNECs. c HRV16 and HRV1B RNA were detected in the cytoplasm of HNECs. HRV1B were more abundant than HRV16 ( $\times 200$ magnification, scale bar: $50 \mu \mathrm{m}$ ). d Fluorescence intensity was higher in HRV1B than in HRV16. Results are presented as the median with and interquartile range from eight subjects. ${ }^{*} p<0.05,{ }^{* *} p<0.01$ in Wilcoxon signed-rank test 

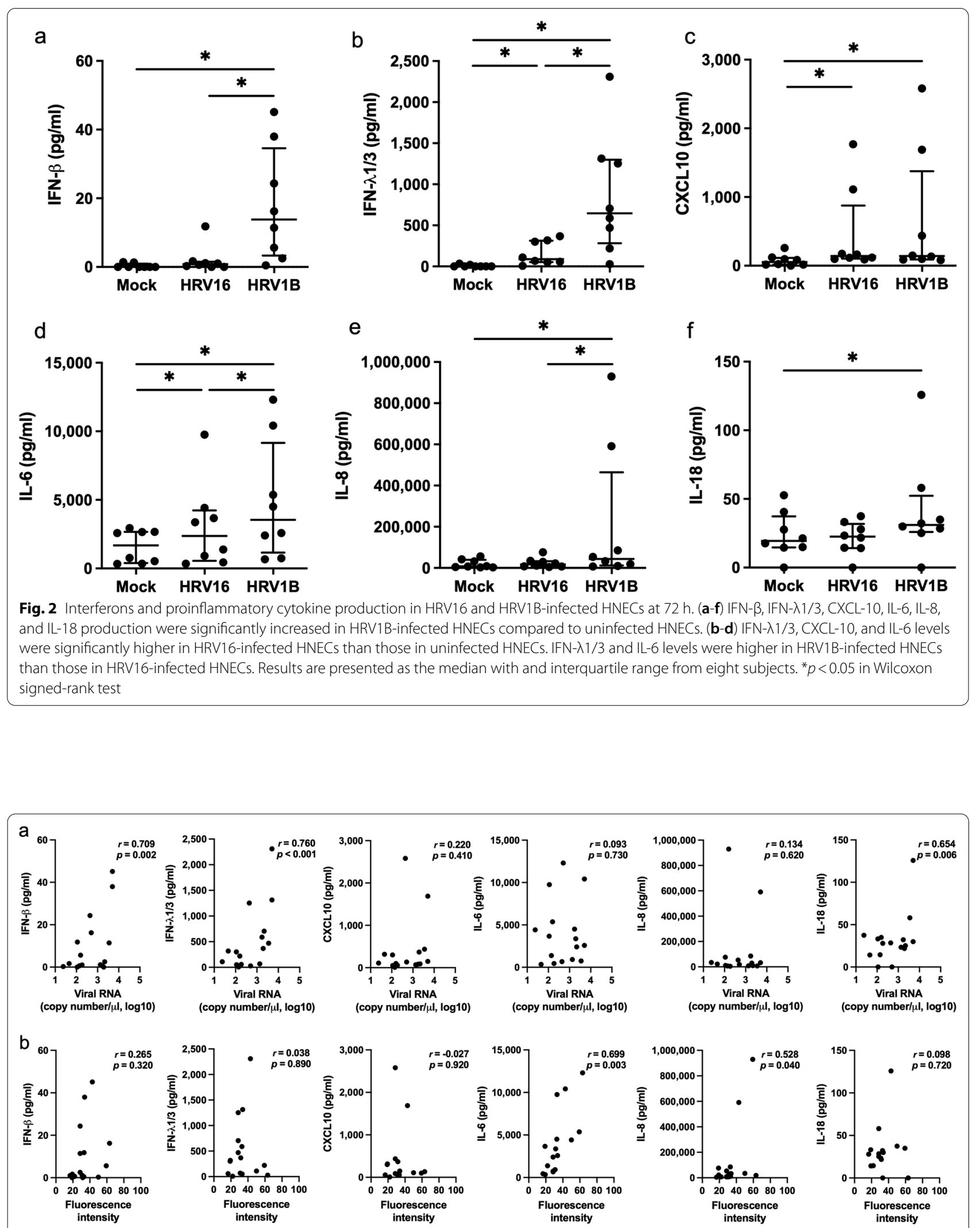

Fig. 3 Correlation between viral RNA (a) and fluorescence intensity of HRV (b) and interferons and proinflammatory cytokine levels in HRV-infected HNECs assessed using Pearson's correlation test 
TLR3 and MDA5 mRNA expression

Although ICAM-1 mRNA levels increased in HRV16 and HRV1B-infected HNECs, there was no statistical significance between them $(p=0.093$ and $p=0.069$, respectively). LDLR mRNA expression levels significantly increased in HRV1B infections ( $p=0.036)$ (Fig. 4a).

TLR3 and MDA5 mRNA levels were significantly higher in HRV1B infection $(p=0.036$ and $p=0.017$, respectively), but not in HRV16 infection ( $p=0.093$ and $p=0.069$, respectively). The increase in RIG-I mRNA levels in both HRV16 and HRV1B infected cells was not significant $(p=0.327$ and $p=0.674$, respectively) (Fig. 4b). However, TLR3, RIG-I, and MDA5 mRNA levels were similar among themselves in HRV16 and HRV1B infected cells.

\section{Transcription factors and their mRNA expression}

NF- $\mathrm{kB}$ mRNA levels were significantly higher in HRV16 and HRV1B infection than in mock $(p=0.036$ and $p=0.012$, respectively) (Fig. 5a). IRF3 and IRF7 mRNA levels in HRV16 and HRV1B infection were not different from the mock (Fig. 5b, c). STAT1 mRNA levels were increased in both HRV16 and HRV1B infection than mock ( $p=0.036$ and $p=0.014$, respectively) whereas STAT2 mRNA levels were increased in HRV1B infection, not in HRV16, than mock $(p=0.040)$ (Fig. $5 \mathrm{~d}$, e), whereas
IRF9 mRNA levels were not increased in HRV16 and HRV1B infection (Fig. 5f).

\section{Discussion}

In this study, HRV1B (minor group of HRV-A) induced stronger immune responses than HRV16 (major group of HRV-A) in the upper airway epithelial cells with more active replication of its viral RNA and increased production of IFN- $\beta$, IFN- $\lambda 1 / 3$, and proinflammatory cytokines.

A previous in vitro study reported differences in immune responses between HRV serotypes in Calu-3 cells, a human lung cancer cell line. HRV14- (species B) and HRV16 (species A)-infected cells showed an increase in IL-6, basic fibroblast growth factor, and IFN$\gamma$-induced protein 10. However, unlike HRV16 cells, HRV14-infected cells showed an increase in macrophage inflammatory protein (MIP)- $1 \beta$, IFN- $\lambda 2 / \mathrm{IL}-28 \mathrm{~A}$, monocyte chemoattractant protein (MCP)-2, and IFN- $\alpha$. The addition of peripheral blood mononuclear cells did not increase MIP-1 $\beta$, IFN- $\lambda 2 / \mathrm{IL}-28 \mathrm{~A}$, and IFN- $\alpha$ levels in HRV16-infected Calu-3 cells, suggesting that altered regulation of cytokines might be a reason for variation in disease severity associated with different HRVs [25]. In our study's ALI culture of upper airway epithelial cells, HRV16-infected cells, showed increase in the cytokines CXCL10, IL-6, and IFN- $\lambda 1 / 3$ levels but no increase in IFN- $\beta$, IL- 8 , and IL-18, whereas HRV1B-infected cells

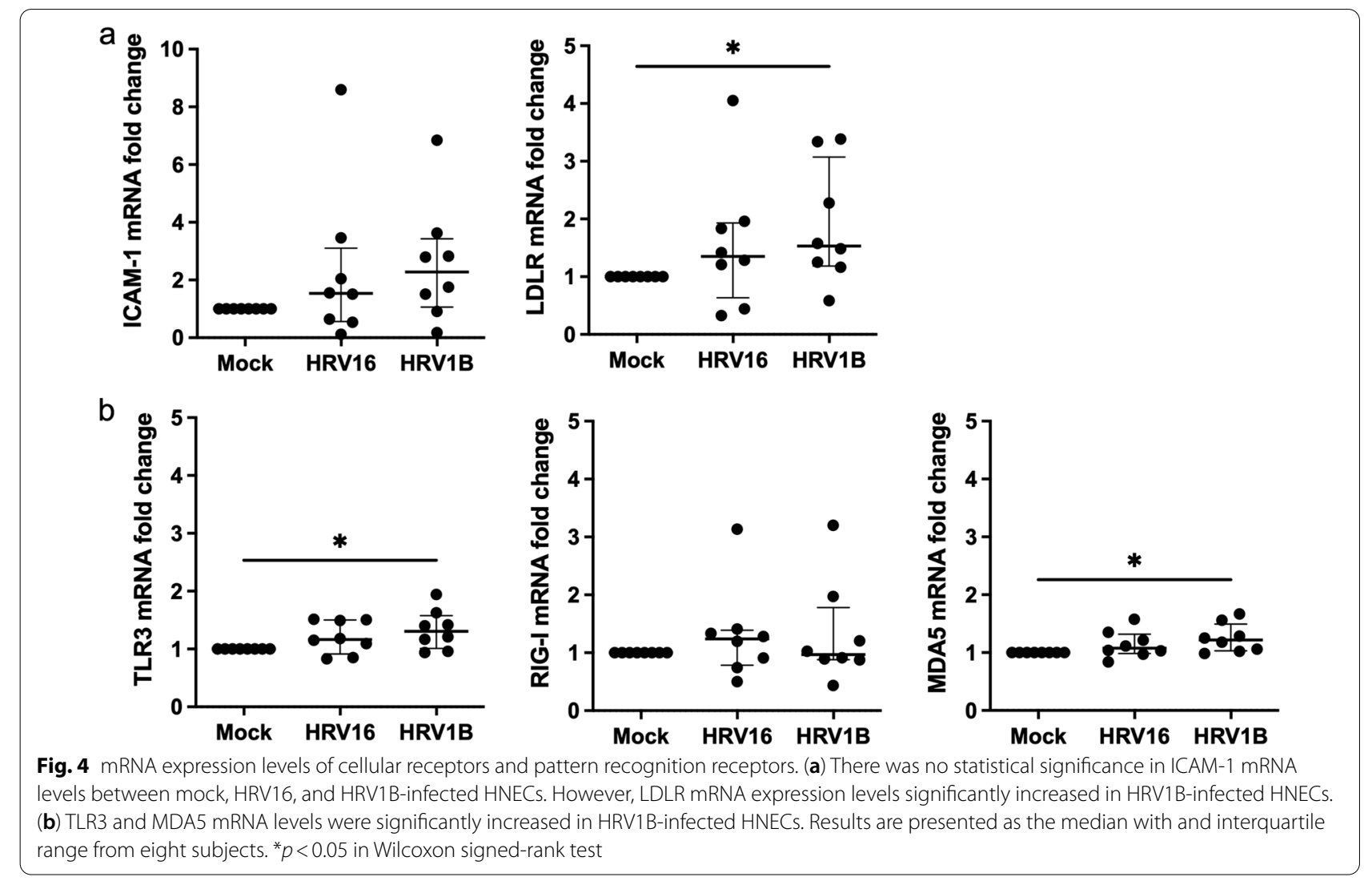



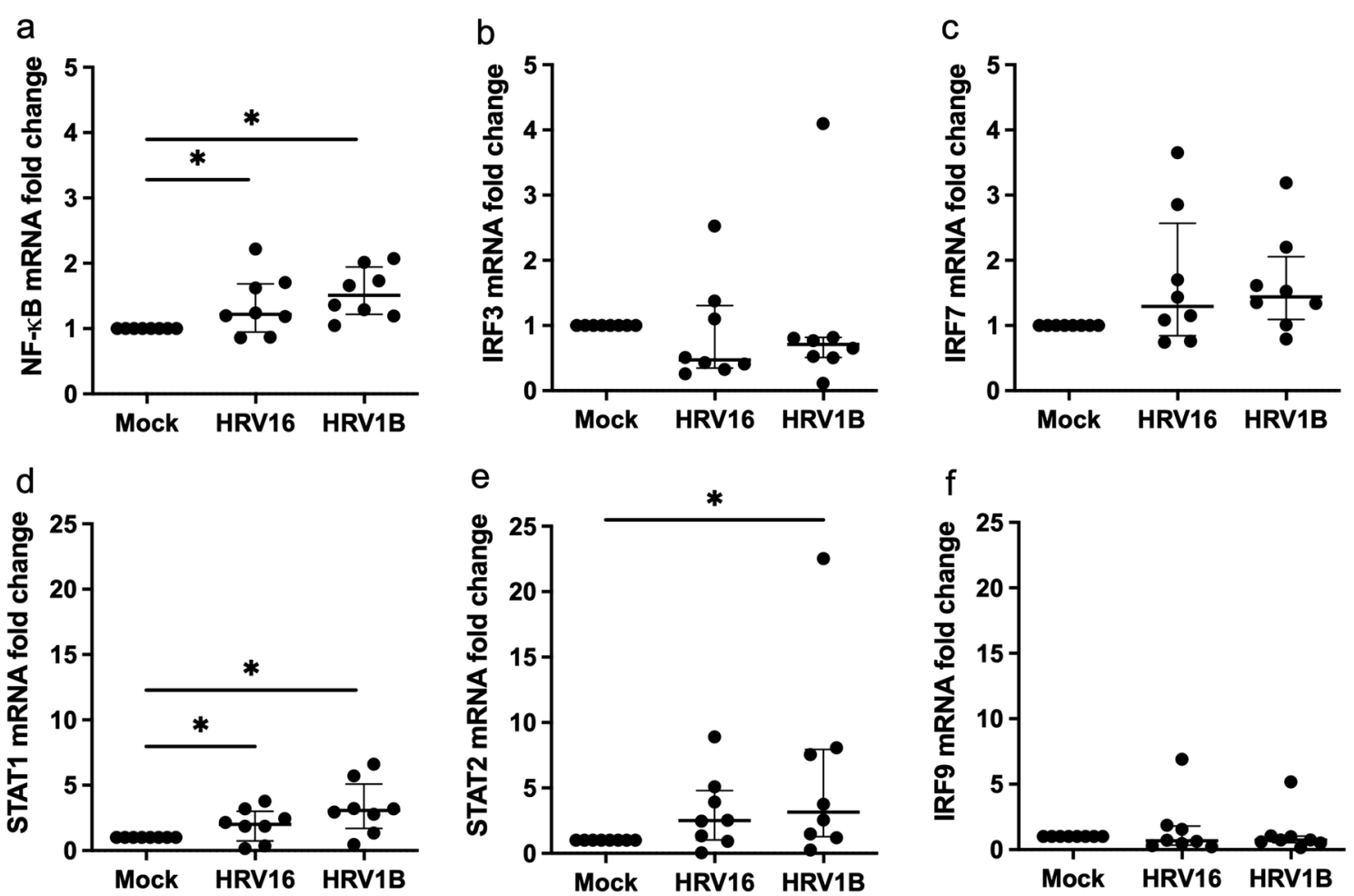

Fig. 5 mRNA expression levels of transcription factors. NF-KB, STAT1, and STAT2 mRNA levels were increased in HRV1B-infected HNECs. (a-f) NF-KB, STAT1, and STAT2 mRNA levels were significantly increased in HRV1B-infected HNECs compared to uninfected HNECs. NF-KB and STAT1 mRNA levels were significantly increased in HRV16-infected HNECs compared to uninfected HNECs. However, IRF3, IRF7, and IRF9 mRNA levels were not increased in HRV16 and HRV1B infection. Results are presented as the median with and interquartile range from eight subjects. ${ }^{*} p<0.05$ in Wilcoxon signed-rank test

showed an increase in IFN- $\beta$, IFN- $\lambda 1 / 3$, CXCL10, IL-6, IL-8, and IL-18 production. Viral RNA and abundance of HRV in the cytoplasm were also higher in HRV1Binfected HNECs than those infected with HRV16. Moreover, IFN- $\beta$, IFN- $\lambda 1 / 3$, and IL-18 levels positively correlated with viral RNA and IL-6 and IL-8 levels correlated with fluorescence intensity of HRV, which suggests that differences in viral replication and proliferation lead to the differences in immune factors production. This difference in viral replication may be caused by differences in the entry of HRV16 and HRV1B into cells, which is reflected by a non-significant increase in ICAM-1 mRNA expression in HRV16-infected HNECs, but a significant increase in LDL-R mRNA expression in HRV1B-infected HNECs. Moreover, TLR3 and MDA5 mRNA levels were higher in HRV1B-infected HNECs, but not in HRV16infected cells. RIG-I mRNA levels were similar in both HRV16 and HRV1B-infected HNECS. Given that TLR3 and MDA5, but not RIG-I, are required for maximal sensing of RV dsRNA and type I IFN signaling pathway [26], the difference in IFN- $\beta$ production between HRV16 and HRV1B-infected HNECs may account for the difference in TLR and MDA5 expression.

Nevertheless, our results may not be broadly applied to other serotypes in HRV-A-major and -minor groups. In a previous study, they compared immune responses between HRV-A55 (major group) and HRV-A49 (minor group) in addition to other highly prevalent respiratory pathogens such as HRV-B, HRV-C, respiratory enteroviruses, influenza virus, respiratory syncytial viruses, and coronaviruses [27]. There were no differences in viral load and chemokine and cytokine levels between HRV-A55 and HRV-A49 in contrast to our result that showed differences between HRV-16 and HRV-1B. These discrepancies may be due to differences in cell source, viral load, and location of sample collection. In our study, nasal epithelial cells from the middle turbinate tissue were used and infected with 0.5 MOI of virus $\left(1.5 \times 10^{5}\right)$, whereas those from nasal polyps were used and infected with a larger load of $1.5 \times 10^{6}$ in their study. Furthermore, viral load was quantified in the cells in our study, while those were measured released 
viruses to apical and basal medium in their study. However, IL-6 and IL-8 levels in the basal medium were different between HRV16 and HRV1B in our study, but not different between HRV-A55 and HRV-A49 in their study. Another study showed the differences in IL-8 and IFN- $\beta$ levels between HRV16 and HRV1B [28]. Therefore, the immune response of HRV may be serotype specific.

IFNs are an important component of the antiviral innate immune response. Many cell types produce both type I IFNs $(\operatorname{IFN}-\alpha / \beta)$ and type III IFN (IFN- $\lambda$ ) in response to a respiratory virus infection, and airway epithelial cells also produce IFN- $\beta$ and IFN- $\lambda$. However, the amount and type of IFNs produced during viral infection depend on the cell types. Airway epithelial cells produce abundant IFN- $\lambda$ in response to respiratory syncytial virus and influenza virus as well as poly I:C (a TLR-3 agonist), whereas IFN- $\beta$ production was less than IFN- $\lambda$. $[23,29$, 30] Likewise, IFN- $\lambda$ was significantly produced in HNECs in response to HRV infection, while IFN- $\beta$ was less produced than IFN- $\lambda$. CD11c + cells may be the source of the sinonasal mucosa [31].

In addition to IFNs, IL-18 is a major proinflammatory cytokine released upon activation of pattern recognition receptors and has broad pathogen-neutralizing effects, enhancing type 1 responses, activating neutrophils, and thereby promoting early innate immune responses [32]. Human bronchial epithelial cells can produce IL-18 in response to HRV infection [33], in our study, HNECs also produce IL-18, which is expected to prime neutrophils and enhance type $1 \mathrm{immune}$ response to eradicate HRV.

$\mathrm{NF}-\mathrm{KB}$ regulates the expression of many genes, including those of cytokines, chemokines, transcription factors, antimicrobial peptides, and IFN-stimulated genes [34-38]. IL-6 and IL-8 production in HRV-infected epithelial cells is mediated by the NF- $\kappa B$-dependent transcriptional activation pathway [11]. In our study, NF- $\mathrm{kB}$ levels increased, both in HRV16 and HRV1B-infected HNECs. However, the increase in IRF3 and IRF7 mRNA levels after HRV infection was not significant. These findings suggest that NF- $\mathrm{kB}$ may be involved in types I and III IFN as well as proinflammatory cytokine production.

In the downstream signaling pathway of type I and III IFNs, Janus activated kinase engaged with IFN receptor phosphorylates both STAT1 and STAT2, leading to the formation of IFN-stimulated gene factor 3 complexes (STAT1-STAT2-IRF9 complexes). These complexes translocate to the nucleus and bind to IFN-stimulated response elements to transcribe IFN-stimulated genes [39]. Compared with HRV16-infected HNECs, a more prominent increase in STAT1 and STAT2 mRNA together with IFN- $\beta$ and IFN- $\lambda 1 / 3$ in HRV1B-infected
HNECs may reflect stronger inflammatory and anti-viral immune responses.

Clinically, compared with the human rhinovirus species HRV-B, HRV-A, and HRV-C have been more strongly associated with moderate to severe illness in infants, and hospitalization for acute respiratory illness and serious illness outcomes in young children [40, 41]. However, while minor group HRV-A exposure was significantly associated with asthma exacerbations in adults, major group HRV-A, HRV-B, HRV-C, and other viruses were not. In addition, neutrophil burden was associated with asthma exacerbations [42]. IL-8, a neutrophil chemokine and activator, is an important factor in the clinical outcome of HRV infection [11]. Levels of IL-8 in nasal lavage fluid from HRV-infected subjects correlated with severity of rhinorrhea and nasal obstruction and peaked at 48 to $72 \mathrm{~h}$ after HRV inoculation [43]. Our study showed that IL-8 production obviously increased in HRV1Binfected HNECs at $72 \mathrm{~h}$ and was higher than IL-8 levels in HRV16-infected HNCEs, suggesting that upper respiratory infection symptoms (similar to asthma exacerbation) may be more severe in HRV1B infection than in HRV16 infection related to neutrophil burden [42]. Based on our results, it is important to find the identity of the HRV species or sequence elements that confer the most pathogenic risk. Further studies are needed regarding the mechanisms that affect antiviral responses and/or induce damage to the airway mucosa associated with neutrophil influx in patients with underlying airway disease, including asthma, COPD, and CRS.

\section{Conclusion}

Our study showed that HRV1B (minor group of HRV-A) replicated more actively and induced increased production of IFN- $\beta$, IFN- $\lambda 1 / 3$, CXCL10, IL-6, IL- 8 , and IL-18 in HNECs, compared with HRV16 (major group of HRVA). Moreover, higher levels of LDL-R, TLR3, MDA5, NF- $\mathrm{kB}$, STAT1, and STAT2 mRNA expression were seen in HRV1B-infected HNECs. These results suggest that selection of the serotype of HRV is very important when designing experiments to identify the immune response to HRV.

\footnotetext{
Abbreviations

HRV: Human rhinovirus; CRS: Chronic rhinosinusitis; ICAM-1: Inter-Cellular Adhesion Molecule 1; LDLR: Low-density lipoprotein receptor; TLR3: Toll-like receptor 3; RIG-I: Retinoic acid-inducible gene I; MDA5: Melanoma differentiation-associated gene 5; IFN: Interferon; CXCL: C-X-C motif chemokine; IL: Interleukin; CCL: Cytokines Chemokine (C-C motif) ligand; HNECs: Human nasal epithelial cells; ALI: Air-liquid Interface; PBS: Phosphate buffered saline; STAT: Signal transducer and activator of transcription; NF-kB: Nuclear factor kappa-light-chain-enhancer of activated B cells; IRF: Interferon regulatory factor; LDH: Lactate dehydrogenase.
} 


\section{Supplementary Information}

The online version contains supplementary material available at https://doi. org/10.1186/s12985-021-01701-1.

Additional file 1. Figure S1. HRV16 RNA, LDH activity, and INF- $\lambda 1 / 3$ and IL-6 levels after HRV1 6 infection in A549 cells. (a) The copy number of HRV 16 was not different between $33^{\circ} \mathrm{C}$ and $37^{\circ} \mathrm{C}$ at $24-96 \mathrm{~h}$ post-infection. $\mathrm{LDH}$ activity also did not differ between $24,48,72$, and $96 \mathrm{~h}$ postinfection. (c) INF- $\lambda 1 / 3$ and IL-6 levels increased consistently from 24 to 72 $\mathrm{h}$ and remained unchanged from 72 to $96 \mathrm{~h}$. Figure S2. Dose-response of HRV16 RNA, LDH activity, and IFN- $\beta$, IFN- $\lambda 1 / 3$, and IL- 6 production from submerged primary nasal epithelial cells after HRV16 infection. (a) At 72 $\mathrm{h}$ post-infection, HRV16 RNA was not different in nasal epithelial cells infected with $0.5 \mathrm{MOI}$ and $1 \mathrm{MOl}$ of HRV16. (b) At 24, 48, and $72 \mathrm{~h}$ postinfection, LDH activity and IFN- $\beta$, IFN- $\lambda 1 / 3$, and IL- 6 production were not different in nasal epithelial cells infected with $0.5 \mathrm{MOI}$ and $1 \mathrm{MOI}$ of HRV16.

\section{Acknowledgements}

We want to thank Shin Ae Kim and Jong Ik Lee for their excellent technical assistance on this project.

\section{Authors' contributions}

JHK conceptualized, conceived the study, analyzed data, and wrote the draft manuscript. JYJ performed experiments. YJJ conceptualized and supervised research works and methods. All authors read and approved the final manuscript.

\section{Funding}

This research was supported by the National Research Foundation of Korea (NRF) grant funded by the Korea government (MSIT), Grant Numbers 2017R1A2B4006950 and 2020R1F1A1071591.

\section{Availability of data and materials}

Available from the corresponding author, upon reasonable request.

\section{Declarations}

\section{Ethics approval and consent to participate}

This study was conducted in accordance with the Declaration of Helsinki and approved by the Institutional Review Board of Asan Medical Center (20170668). All participants provided written informed consent for inclusion before they participated in the study.

\section{Consent for publication}

Not applicable.

\section{Competing interests}

All authors of this manuscript declare they have no conflict of interest.

\section{Received: 9 September 2021 Accepted: 11 November 2021} Published online: 27 November 2021

\section{References}

1. Jang YJ, Kwon HJ, Park HW, Lee BJ. Detection of rhinovirus in turbinate epithelial cells of chronic sinusitis. Am J Rhinol. 2006;20:634-6.

2. Cho GS, Moon BJ, Lee BJ, et al. High rates of detection of respiratory viruses in the nasal washes and mucosae of patients with chronic rhinosinusitis. J Clin Microbiol. 2013;51:979-94.

3. Brownlee JW, Turner RB. New developments in the epidemiology and clinical spectrum of rhinovirus infections. Curr Opin Pediatr. 2008;20:67-71.

4. Gern JE. The ABCs of rhinoviruses, wheezing, and asthma. J Virol. 2010;84:7418-26.

5. Turner RB, Lee W-M. Rhinovirus. In: Richman DD, Whitley RJ, Hayden FG, editors. Clinical virology. 3rd ed. Washington: ASM Press; 2009. p. 1063-82.
6. Miller EK, Lu X, Erdman DD, et al. New vaccine surveillance network. J Infect Dis. 2007;195:773-81.

7. Peltola V, Waris M, Osterback R, Susi P, Ruuskanen O, Hyypiä T. Rhinovirus transmission within families with children: incidence of symptomatic and asymptomatic infections. J Infect Dis. 2008;197:382-9.

8. Palmenberg AC, Spiro D, Kuzmickas R, et al. Sequencing and analyses of all known human rhinovirus genomes reveal structure and evolution. Science. 2009:324:55-9.

9. Bochkov YA, Watters K, Ashraf S, et al. Cadherin-related family member 3, a childhood asthma susceptibility gene product, mediates rhinovirus $C$ binding and replication. Proc Natl Acad Sci USA. 2015;112:5485-90.

10. Fuchs R, Blaas D. Uncoating of human rhinoviruses. Rev Med Virol. 2010;20(5):281-97.

11. Vareille M, Kieninger E, Edwards MR, Regamey N. The airway epithelium: soldier in the fight against respiratory viruses. Clin Microbiol Rev. 2011:24:210-29.

12. Pierangeli A, Statzu M, Nenna R, et al. Interferon Lambda Receptor 1 (IFNL1R) Transcript Is Highly Expressed in Rhinovirus Bronchiolitis and Correlates With Disease Severity. J Clin Virol. 2018;102:101-9.

13. Schuler BA, Schreiber MT, Li L, et al. Major and minor group rhinoviruses elicit differential signaling and cytokine responses as a function of receptor-mediated signal transduction. PLoS ONE. 2014;9:e93897.

14. Bartlett NW, Walton RP, Edwards MR, et al. Mouse models of rhinovirusinduced disease and exacerbation of allergic airway inflammation. Nat Med. 2008;14:199-204.

15. Lee SB, Song JA, Choi GE, Kim HS, Jang YJ. Rhinovirus infection in murine chronic allergic rhinosinusitis model. Int Forum Allergy Rhinol. 2016;6:1131-8.

16. Jang YJ, Wang JH, Kim JS, Kwon HJ, Yeo NK, Lee BJ. Levocetirizine inhibits rhinovirus-induced ICAM-1 and cytokine expression and viral replication in airway epithelial cells. Antiviral Res. 2009:81(3):226-33.

17. Yeo NK, Jang YJ. Rhinovirus infection-induced alteration of tight junction and adherens junction components in human nasal epithelial cells. Laryngoscope. 2010;120:346-52.

18. Kim JH, Kim YS, Cho GS, Kim NH, Gong CH, Lee BJ, Jang YJ. Human rhinovirus-induced proinflammatory cytokine and interferon-beta responses in nasal epithelial cells from chronic rhinosinusitis patients. Allergy Asthma Immunol Res. 2015;7:489-96.

19. Wang JH, Kwon HJ, Jang YJ. Rhinovirus enhances various bacterial adhesions to nasal epithelial cells simultaneously. Laryngoscope. 2009;119:1406-11.

20. Wang JH, Lee SH, Kwon HJ, Jang YJ. Clarithromycin inhibits rhinovirusinduced bacterial adhesions to nasal epithelial cells. Laryngoscope. 2010;120:193-9.

21. Min JY, Shin SH, Kwon HJ, Jang YJ. Levocetirizine inhibits rhinovirusinduced bacterial adhesion to nasal epithelial cells through downregulation of cell adhesion molecules. Ann Allergy Asthma Immunol. 2012;26:10844-8.

22. Lee $\mathrm{SB}$, Yi JS, Lee BJ, Gong $\mathrm{CH}$, Kim NH, Joo CH, Jang YJ. Human rhinovirus serotypes in the nasal washes and mucosa of patients with chronic rhinosinusitis. Int Forum Allergy Rhinol. 2015;5:197-203.

23. Kim HJ, Kim CH, Ryu JH, et al. Reactive Oxygen Species Induce Antiviral Innate Immune Response Through IFN- $\lambda$ Regulation in Human Nasal Epithelial Cells. Am J Respir Cell Mol Biol. 2013;49:855-65.

24. Mosser AG, Brockman-Schneider R, et al. Similar frequency of rhinovirus-infectible cells in upper and lower airway epithelium. J Infect Dis. 2002;185:734-43.

25. Rajan D, Gaston KA, McCracken CE, Erdman DD, Anderson LJ. Response to Rhinovirus infection by human airway epithelial cells and peripheral blood mononuclear cells in an in vitro two-chamber tissue culture system. PLoS ONE. 2013;8:e66600.

26. Wang Q, Nagarkar DR, Bowman ER, et al. Role of double-stranded RNA pattern recognition receptors in rhinovirus-induced airway epithelial cell responses. J Immunol. 2009;183:6989-97.

27. Essaidi-Laziosi M, Brito F, Benaoudia S, et al. Propagation of respiratory viruses in human airway epithelia reveals persistent virus-specific signatures. J Allergy Clin Immunol. 2018;141:2074-84.

28. Stokes CA, Kaur R, Edwards MR, et al. Human rhinovirus-induced inflammatory responses are inhibited by phosphatidylserine containing liposomes. Mucosal Immunol. 2016;9:1303-16. 
29. Wang J, Oberley-Deegan R, Wang S, et al. Differentiated human alveolar type II cells secrete antiviral IL-29 (IFN-lambda 1) in response to influenza A infection. J Immunol. 2009;182(3):1296-304.

30. Ioannidis I, Ye F, McNally B, Willette M, Flaño E. Toll-like receptor expression and induction of type I and type III interferons in primary airway epithelial cells. J Virol. 2013;87(6):3261-70.

31. Jang YJ, Lim JY, Kim S, et al. Enhanced interferon- $\beta$ response contributes to eosinophilic chronic rhinosinusitis. Front Immunol. 2018;9:2330.

32. Labzin LI, Lauterbach MA, Latz E. Interferons and inflammasomes: Cooperation and counterregulation in disease. J Allergy Clin Immunol. 2016;138:37-46.

33. Shi L, Manthei DM, Guadarrama AG, Lenertz LY, Denlinger LC. Rhinovirus-induced IL-1 beta release from bronchial epithelial cells is independent of functional P2X7. Am J Respir Cell Mol Biol. 2012;47:363-71.

34. Courtine E, Cagnard N, Mazzolini J, et al. Combined loss of cRel/p50 subunits of NF-kB leads to impaired innate host response in sepsis. Innate Immun. 2012;18:753-63.

35. Grigoriadis G, Zhan Y, Grumont RJ, et al. The Rel subunit of NF-kappaBlike transcription factors is a positive and negative regulator of macrophage gene expression: distinct roles for Rel in different macrophage populations. EMBO J. 1996;15:7099-107.

36. Sanjabi S, Hoffmann A, Liou HC, Baltimore D, Smale ST. Selective requirement for c-Rel during IL-12 P40 gene induction in macrophages. Proc Natl Acad Sci U S A. 2000;97:12705-10.

37. Wang $X$, Wang J, Zheng $H$, et al. Differential requirement for the IKK $\beta$ / NF-KB signaling module in regulating TLR-versus RLR-induced type 1 IFN expression in dendritic cells. J Immunol. 2014;193:2538-45.
38. Werner SL, Barken D, Hoffmann A. Stimulus specificity of gene expression programs determined by temporal control of IKK activity. Science. 2005;309:1857-61.

39. Platanias LC. Mechanisms of type-l- and type--I-interferon-mediated Signalling. Nat Rev Immunol. 2005;5:375-86.

40. Lee WM, Lemanske RF Jr, Evans MD, et al. Human rhinovirus species and season of infection determine illness severity. Am J Respir Crit Care Med. 2012;186:886-91.

41. Iwane MK, Prill MM, Lu X, et al. Human rhinovirus species associated with hospitalizations for acute respiratory illness in young US children. J Infect Dis. 2011;204:1702-10.

42. Denlinger LC, Sorkness RL, Lee WM, et al. Lower airway rhinovirus burden and the seasonal risk of asthma exacerbation. Am J Respir Crit Care Med. 2011:184:1007-14.

43. Turner RB, Weingand KW, Yeh CH, Leedy DW. Association between interleukin-8 concentration in nasal secretions and severity of symptoms of experimental rhinovirus colds. Clin Infect Dis. 1998;26:840-6.

\section{Publisher's Note}

Springer Nature remains neutral with regard to jurisdictional claims in published maps and institutional affiliations.
Ready to submit your research? Choose BMC and benefit from:

- fast, convenient online submission

- thorough peer review by experienced researchers in your field

- rapid publication on acceptance

- support for research data, including large and complex data types

- gold Open Access which fosters wider collaboration and increased citations

- maximum visibility for your research: over 100M website views per year

At BMC, research is always in progress.

Learn more biomedcentral.com/submissions 